\title{
Physiological and Transcriptional Changes of Three Citrus Rootstock Seedlings under Iron Deficiency
}

\author{
Lina Fu', , Qingqing Zhu ${ }^{1,2}$, Yinya Sun ${ }^{1,2}$, Wei Du ${ }^{1,2}$, Zhiyong Pan ${ }^{1,2 *}$ and Shu'ang Peng ${ }^{1,2 *}$ \\ ${ }^{1}$ Key Laboratory of Horticultural Plant Biology, Ministry of Education, Huazhong Agricultural University, Wuhan, China, \\ ${ }^{2}$ Key Laboratory of Horticultural Crop Biology and Genetic Improvement (Central Region), Ministry of Agriculture, Wuhan, \\ China
}

Iron is an essential micronutrient for plants, and plants have evolved adaptive mechanisms to improve iron acquisition from soils. Grafting on iron deficiency-tolerant rootstock is an effective strategy to prevent iron deficiency-chlorosis in fruit-tree crops. To determine the mechanisms underlying iron uptake in iron deficiency, two iron deficiency-tolerant citrus rootstocks, Zhique $(Z Q)$ and Xiangcheng $(X C)$, as well as iron deficiency-sensitive rootstock trifoliate orange (TO) seedlings were studied. Plants were grown in hydroponics system for 100 days, having $50 \mu \mathrm{M}$ iron (control) and $0 \mu \mathrm{M}$ iron (iron deficiency) nutrient solution. Under iron deficiency, more obvious

OPEN ACCESS

Edited by:

Felipe Klein Ricachenevsky, Universidade Federal de Santa Maria,

Brazil

Reviewed by: Youry Pii,

Free University of Bozen-Bolzano, Italy Prashant S. Hosmani,

Boyce Thompson Institute for Plant Research, United States

${ }^{*}$ Correspondence: Zhiyong Pan zypan@mail.hzau.edu.cn Shu'ang Peng shuangpeng428@126.com

Specialty section: This article was submitted to Plant Nutrition,

a section of the journal Frontiers in Plant Science

Received: 31 March 2017 Accepted: 07 June 2017 Published: 26 June 2017

Citation:

Fu L, Zhu Q, Sun Y, Du W, Pan Z and Peng S (2017) Physiological and Transcriptional Changes of Three Citrus Rootstock Seedlings under Iron

Deficiency. Front. Plant Sci. 8:1104. doi: 10.3389/fpls.2017.01104 visual symptoms of iron chlorosis were observed in the leaves of $\mathrm{TO}$, whereas slight symptoms were observed in $\mathrm{ZQ}$ and $\mathrm{XC}$. This was further supported by the lower chlorophyll concentration in the leaves of TO than in leaves of $Z Q$ and $X C$. Ferrous iron showed no differences among the three citrus rootstock roots, whereas ferrous iron was significantly higher in leaves of $Z Q$ and $X C$ than $T O$. The specific iron absorption rate and leaf iron proportion were significantly higher in $Z Q$ and $X C$ than in $T O$, suggesting the iron deficiency tolerance can be explained by increased iron uptake in roots of $Z Q$ and $X C$, allowed by subsequent translocation to shoots. In transcriptome analysis, 29, 298, and 500 differentially expressed genes (DEGs) in response to iron deficiency were identified in $Z Q, X C$, and $T O$, respectively (Fold change $\geq 2$ and Probability $\geq 0.8$ were used as thresholds to identify DEGs). A Gene Ontology analysis suggested that several genotype-specific biological processes are involved in response to iron deficiency. Genes associated with cell wall biosynthesis, ethylene and abscisic acid signal transduction pathways were involved in iron deficiency responses in citrus rootstocks. The results of this study provide a basis for future analyses of the physiological and molecular mechanisms of the tolerance of different citrus rootstocks to iron deficiency.

Keywords: iron deficiency, citrus rootstocks, iron concentration, transcriptome analysis, gene expression regulation

\section{INTRODUCTION}

Iron is an essential nutrient for plant growth since it takes part in most important primary metabolic processes, including photosynthesis, respiratory electron transport, nitrogen assimilation, and so on. Although the total iron content in soil is relatively high, its acquisition by crop plants is often limited owing to its low bioavailability in well-oxygenated and alkaline 
soil conditions (Mimmo et al., 2014). Chlorosis in leaves and decreased yield resulting from iron deficiency are serious problems for crop production.

Plants have developed two adaptive mechanisms under iron deficiency conditions: a reduction-based strategy I and a chelation-based Strategy II (Römheld and Marschner, 1986). In strategy I plants (dicotyledonous and non-grass monocotyledonous species), protons are secreted into the rhizosphere via plasma membrane-bound $\mathrm{H}^{+}$-ATPases in roots, which lowers the rhizosphere soil $\mathrm{pH}$ (Dell'Orto et al., 2000; Santi and Schmidt, 2009). Meanwhile ferric iron is reduced to the ferrous form by ferric chelate reductase (FCR) at the root surface (Robinson et al., 1999), and ferrous iron is then transported across root cell membranes through the iron-regulated transporter (IRT) (Eide et al., 1996). Strategy II plants (graminaceous species) secrete ferric-chelating substances, such as phytosiderophores, combine with ferric iron; the ironsiderophore complex is taken up by an oligopeptide transporter, Yellow stripe 1 (Curie et al., 2001). It is worth noting that most of these results have been obtained in model plants, and the adaptive mechanism of iron deficiency, is poorly understand in perennial woody plants.

Citrus is a commercially important fruit tree in the world, and most cultivars are susceptible to low iron bioavailability in calcareous soils (Carpena-Artes et al., 1995). Iron-fertilizer is usually used to supply adequate amounts of crop-available iron (Shenker and Chen, 2005; Rombolà and Tagliavini, 2006; Bacaicoa and García-Mina, 2009). However, iron deficiency chlorosis is difficult to correct owing to the rapid transformation of iron -fertilizers to an unavailable form in the soil (Fernández et al., 2004). Moreover, iron fertilizers not only increase costs, but also damage the environment. Beside iron-fertilizers, the microorganisms could increase bioavailability of the iron in soil, and they modulate iron acquisition in plants by an increased expression of typical genes related to iron deficiency response (Pii et al., 2015, 2016; Terrazas et al., 2016). Further studies are needed to better understand the interactions of plant-microorganismsoil for the acquisition of iron in calcareous soils.

Selecting iron deficiency-tolerant rootstocks is believed to be an effective and environment friendly strategy to minimize the iron cholorosis in the citrus industry (Ksouri et al., 2006, 2007; Molassiotis et al., 2006). Several recent studies have screened citrus rootstocks tolerant to iron deficiency based on physiological and morphological indexes (Pestana et al., 2005; Castle et al., 2009; Martínez-Cuenca et al., 2013). For example, compared with Carrizo citrange, iron deficiency-tolerant Cleopatra mandarin has a higher root ferric reduction rate and accumulates more iron in the root apoplast. Molecular responses have also been investigated by monitoring transcript expression in different citrus rootstocks. Genes involved in cell wall modification, photosynthesis, and oxidative stress are found significantly up-regulated under iron deficiency in the commonly used rootstock Poncirus trifoliata (L.) Raf (Forner-Giner et al., 2010). A set of genes associated with oxidative stress, hormone metabolism, and protein turnover are involved in iron deficiency acclimation by comparing iron deficiency-tolerant (Carrizo citrange) and iron deficiency-sensitive (Swinglecitrumelo) rootstocks, planted in calcareous soils (Licciardello et al., 2013).

In our previous study, we found that Zhique (ZQ), a novel citrus rootstock native to China, shows strong tolerance to iron deficiency in calcareous soil (Fu et al., 2016). Here, to further clarify the mechanism underlying the tolerance to iron deficiency in ZQ, an iron deficiency-sensitive rootstock trifoliate orange (TO) and a known iron deficiency-tolerant rootstock Xiangcheng (XC) were used as samples together, and the physiological and transcriptional responses of these three materials were investigated upon iron deficiency treatment.

\section{MATERIALS AND METHODS}

\section{Plant Culture}

Seeds of Zhique (Citrus wilsonii Tanaka) were obtained from Chenggu Fruit Industry Technical Guidance Station, seeds of Xiangcheng (C. junos Sieb. ex Tanaka) were collected and provided by the Institute of Horticulture Research, Sichuan Provincial Academy of Agricultural Science, China, and seeds of TO [P. trifoliate (L.) Raf.] were obtained from the National Citrus Breeding Center in Huazhong Agricultural University, China. As described in our previous work (An et al., 2012), seeds of these three citrus rootstocks were surface-sterilized for $15 \mathrm{~min}$ in a $5 \%$ sodium hypochlorite solution. The seeds were placed on a porcelain tray with moistened gauze and transferred to an incubator at $30^{\circ} \mathrm{C}$ until germination. They were then cultivated in plastic pots filled with vermiculite. These seeds were grown in vermiculite until seedlings with four true leaves. Uniform size seedlings of each rootstock were selected, transferred to hydroponic culture medium containing 1/4 strength Hoagland's nutrient solution (Hoagland and Arnon, 1950), and kept for about 3 weeks until new roots grew. Afterward, the seedlings were grown in modified Hoagland's nutrient solution for 100 days containing either $50 \mu \mathrm{M}$ iron-EDTA (control) or $0 \mu \mathrm{M}$ ironEDTA (iron deficiency). The $\mathrm{pH}$ was adjusted to 6.0 with $\mathrm{NaOH}$ for both control and iron deficiency treatments. The solution was ventilated for $20 \mathrm{~min}$ every $2 \mathrm{~h}$ and replaced once a week. The physiology experiment was kept until the symptom of iron deficiency was observed (about 100 days iron deficiency treatment). Moreover, to detect the iron response and expression of key genes in experimental rootstocks, root samples at a length of $2 \mathrm{~cm}$ from the apex were randomly collected at $0 \mathrm{~h}, 24,48,72$, and $96 \mathrm{~h}$ of iron deficiency treatments.

\section{Measurement of Plant Growth Parameters}

At the end of the experiment (100 days treatment), nine plants per treatment were harvested randomly and were rinsed with deionized water. Then the samples were divided into leaf, stem, and root samples. Leaf area $\left(\mathrm{cm}^{2}\right)$ was determined using a leaf area meter (Li-3100C; LI-COR Biosciences Inc., Lincoln, NE, United States). The root samples were scanned using an Epson digital scanner (Expression 10000XL 1.0; Epson Inc., Nagano, Japan) and images were analyzed using WinRhizo Pro (S) version 2009c (Regent Instruments Inc., Quebec, Canada). The root traits 
examined included total root length $(\mathrm{cm})$, root surface area $\left(\mathrm{cm}^{2}\right)$, root volume $\left(\mathrm{cm}^{3}\right)$ and root number. The fresh materials were placed into a forced air oven at $105^{\circ} \mathrm{C}$ for $15 \mathrm{~min}$, and then at $75^{\circ} \mathrm{C}$ until constant weights were reached to determine dry weights (g). All dried samples were ground into a fine powder to determine iron concentration in various tissues. Seedling height $(\mathrm{cm})$ and taproot length $(\mathrm{cm})$ were measured using a measuring scale.

\section{Chlorophyll Content Determination}

Chlorophyll content concentration was measured according to Fu et al. (2016). Chlorophyll concentration was calculated according to the following formulae:

$$
\begin{aligned}
& \text { Chlorophylla }\left(\mathrm{mgL}^{-1}\right)=12.7\left(\mathrm{OD}_{663}\right)-2.69\left(\mathrm{OD}_{644}\right) \\
& \text { Chlorophyllb }\left(\mathrm{mgL}^{-1}\right)=22.9\left(\mathrm{OD}_{644}\right)-4.68\left(\mathrm{OD}_{663}\right) \\
& \text { Chlorophyll content of the leaf }\left(\mathrm{mgg}^{-1} \mathrm{FW}\right) \\
& =(\text { Chlorophyll concentration } \times \text { extraction solution volume } \\
& \quad \times \text { dilution ratio }) / \text { fresh weight. }
\end{aligned}
$$

\section{Iron Concentration Determination}

Total iron and ferrous iron concentrations in root, stem, and leaf samples were determined by different methods (Fu et al., 2016). The iron distribution is expressed as the iron content (concentration $\times$ dry weight) in one plant part relative to the total plant iron content. The ratio of the iron concentrations in different plant parts represents the ability of the plant to transport iron from the root to shoot, or the ability of the shoot to distribute iron to various shoot parts. Specific uptake rate of iron was calculated according to the equation of Bellaloui and Brown (1998) as follows:

Specific uptake rate $\left(\mu g \mathrm{~g}^{-1} \mathrm{~d}^{-1}\right)=\left[\left(\ln \mathrm{R}_{2}-\ln \mathrm{R}_{1}\right) /\right.$ $\left.\left(\mathrm{T}_{2}-\mathrm{T}_{1}\right)\right] \times\left[\left(\mathrm{M}_{2}-\mathrm{M}_{1}\right) /\left(\mathrm{R}_{2}-\mathrm{R}_{1}\right)\right]$, where $\mathrm{R}_{1}$ and $\mathrm{R}_{2}$ are the initial and final root dry weights, respectively; $\mathrm{T}_{2}$ and $\mathrm{T}_{1}$ are the treatment durations; $M_{1}$ and $M_{2}$ are the initial $\left(T_{1}\right)$ and final $\left(T_{2}\right)$ iron contents per plant.

\section{Transcript Analysis}

For the transcript analysis, roots with length of $2 \mathrm{~cm}$ from the tips were randomly collected after $50 \mu \mathrm{M}$ Fe-EDTA $(+\mathrm{Fe})$ or $0 \mu \mathrm{M}$ Fe-EDTA (-Fe) treatments for $24 \mathrm{~h}$, and were immediately frozen in liquid nitrogen and stored at $-80^{\circ} \mathrm{C}$ for further analysis.

Roots from nine plants were pooled as an independent biological replicate and three independent biological replicates were used in transcriptomic analysis. RNAs were extracted from $\mathrm{ZQ}, \mathrm{XC}$ and TO roots and used to construct cDNA libraries, with three replicates for each treatment ( 6 for $\mathrm{ZQ}, 6$ for $\mathrm{XC}$, and 6 for TO). RNA library construction and sequencing experiments were conducted at Huada Genomics Co. Ltd. (Shenzhen, China). During the QC step, the Agilent 2100 Bioanalyzer (Santa Clara, CA, United States) and ABI StepOnePlus Real-Time PCR System were used for qualitative and quantitative characterization of the sample library. The library products were sequenced using the
IlluminaHiSeq ${ }^{\text {TM }} 2000$ (San Diego, CA, United States). The raw reads in fasta format were deposited in the NCBI Sequence Read Archive (SRA) database ${ }^{1}$ and the corresponding run accession number (SRR5272210) was offered.

As there are some adaptor sequences and/or low quality reads present in the raw reads, data filtering has been carried out by the SOAPnuke ${ }^{2}$ to obtain high quality reads as the clean reads (clean data). The procedure included following steps: (1) Remove reads with adaptor sequences; (2) Remove reads in which the percentage of unknown bases $(\mathrm{N})$ is greater than $10 \%$; (3) Remove low quality reads. If the percentage of the low quality base (base with quality value $\leq 5$ ) is greater than $50 \%$ in a read, we define this read as low quality. Subsequently, the proportion of clean reads in raw reads of the libraries was classified. The clean reads were mapped to the sweet orange genome ${ }^{3}$ (Xu et al., 2012) using SOAP (Li et al., 2009), and the NCBI database ${ }^{4}$. Mismatches at no more than 2 bases were allowed in the alignment. The reads mapped to reference sequences from multiple genes were filtered. Subsequently, a sequencing saturation analysis and randomness assessments were carried out (Supplementary Figures S2-S4). RSEM is a quantification tool that computed Maximum likelihood abundance estimates using the Expectation Maximization (EM) algorithm for its statistical model, including the modeling of paired-end $(\mathrm{PE})$ and variablelength reads, fragment length distributions, and quality scores, to determine which transcripts are isoforms of the same gene (Li and Dewey, 2011).

FPKM method is used in calculating expression level, the formula is following: $\mathrm{FPKM}=10^{6} \mathrm{C} /\left(\mathrm{NL} / 10^{3}\right)$. Here $\mathrm{FPKM}(\mathrm{A})$ is the expression level of gene $\mathrm{A}, \mathrm{C}$ is number of reads that uniquely aligned to gene $\mathrm{A}, N$ is total number of reads that uniquely aligned to all genes, and $L$ is number of bases of gene A. The FPKM method is able to eliminate the influence of different gene length and sequencing discrepancy on the calculation of gene expression level. Therefore, the FPKM values can be directly used for comparing the difference of gene expression among samples.

If there is more than one transcript for a gene, the longest one is used to calculate its expression level and coverage. A fold change $\geq 2$ and Probability $\geq 0.8$ were used as thresholds to identify DEGs. Gene Ontology (GO) annotation was performed by using Blast2GO software (GO association done by a BLASTX against the NCBI nr database). For the pathway enrichment analysis, all DEGs were mapped to pathway terms in the KEGG database $^{5}$. Main functional categories for differentially expressed genes were analyzed according to MapMan functional plant categories (Lohse et al., 2014).

\section{Quantitative Real-Time PCR Analysis}

The detailed protocol for the quantitative real-time PCR analysis procedure was described previously (An et al., 2012). Briefly, total RNA was isolated with TRIzol reagent (RNAiso Plus;

\footnotetext{
${ }^{1}$ https://www.ncbi.nlm.nih.gov/Traces/sra_sub/

${ }^{2}$ http://soap.genomics.org.cn/

${ }^{3}$ http://citrus.hzau.edu.cn/orange/index.php

${ }^{4}$ http://www.ncbi.nlm.nih.gov/

${ }^{5}$ http://www.genome.jp/kegg/
} 
Takara, Shiga, Japan) according to the protocol provided by the manufacturer. RNA quality $\left(\mathrm{OD}_{260} / \mathrm{OD}_{280}\right.$ ratio) and concentration were measured. Based on the estimated RNA concentration, one microgram of total RNA was used per cDNA synthesis reaction to avoid potential bias in the transcript evaluation. The actin gene was used for normalization. The primer sequences are listed in Supplementary Table S1. Quantitative real-time PCRs reactions were performed with SYBR Green PCR Master Mix (SYBR Premix Ex Taq II; Takara) and analyzed using the Real-Time System. Reactions were initiated with an initial incubation at $50^{\circ} \mathrm{C}$ for $2 \mathrm{~min}$ and $95^{\circ} \mathrm{C}$ for $10 \mathrm{~min}$, followed by 40 cycles of $95^{\circ} \mathrm{C}$ for $15 \mathrm{~s}$, and $60^{\circ} \mathrm{C}$ for $30 \mathrm{~s}$. Four technical replicates were assayed for all PCRs. The Livak method (Livak and Schmittgen, 2001) was employed to calculate the relative expression levels.

\section{Statistical Analysis}

All experiments data were tested for differences using analysis of variance, and mean separation within samples by Duncan's multiple range test (SAS version 8.1; SAS Institute, Cary, NC, United States).

\section{RESULTS}

\section{Morphological and Growth Parameters of $Z Q$ and XC Differed from Those of TO}

Three citrus rootstock seedlings, ZQ (Zhique, tolerant to iron deficiency), $\mathrm{XC}$ (Xiangcheng, tolerant to iron deficiency) and TO (trifoliate orange, sensitive to iron deficiency), were grown in hydroponic culture and subjected to iron deficiency. After 100 days of iron deficiency, the young leaves of TO showed obvious interveinal chlorosis under iron deficiency conditions. By contrast, the $\mathrm{ZQ}$ and $\mathrm{XC}$ leaves showed only slight chlorosis under iron deficiency treatments (Figure 1A). Consistent with the observed phenotypes, the reduction in chlorophyll a and b content was greater in TO (41 and 41\%) than in ZQ (1 and 16\%) and XC (31 and 32\%) under iron deficiency conditions (Figures $\mathbf{1 B}, \mathbf{C}$ ). The symptoms of iron deficiency and the reductions in chlorophyll $\mathrm{a}$ and $\mathrm{b}$ content were also obviously greater in $\mathrm{XC}$ than in ZQ. However, no differences were detected in leaf dry weight and leaf area among the three rootstocks under iron deficiency (Figures 1D,E).

The stem morphologies are shown in Supplementary Figure S1. No significant differences were found in stem length and stem dry weight among ZQ, XC, and TO.

As shown in Figure 2, the roots morphology of the three rootstock seedlings exhibited no obvious differences under iron deficiency treatment as compared with control roots. However, under iron deficiency conditions, the root number were significantly reduced in $\mathrm{TO}$, while no difference was detected in $\mathrm{ZQ}$ and $\mathrm{XC}$ root growth parameters under iron deficiency treatment as compared with control roots, including total root length, root surface area, root volume, and root numbers (Figure 2).

\section{Specific Fe Absorption Rate Was Higher in Roots of $Z Q$ and $X C$ than in Roots of TO}

Total and ferrous iron concentrations in different tissues were determined to explore iron uptake and allocation in citrus seedlings. As shown in Figures 3A,D, the total and ferrous iron in $\mathrm{ZQ}$ and $\mathrm{XC}$ showed no differences in leaves from those of control plant leaves under iron deficiency treatments. However, in leaves of TO both total and ferrous iron were significantly lower than those of control plant leaves. In stems under iron deficiency treatments total and ferrous iron were significantly decreased in $\mathrm{ZQ}$ and XC (Figures 3B,E). In roots, total and ferrous iron level in all the three rootstocks were significantly decreased under iron deficiency conditions (Figures 3C,F).

Iron content per plant and specific iron absorption rate in all the three genotypes were significantly lower under iron deficiency conditions than in control seedlings (Figure 4). It is worth noting that the specific iron absorption rate was higher in ZQ and XC than in TO under iron deficiency (though the difference between ZQ and TO was not rich a significant), but no difference among the three rootstocks were detected under control conditions (control). With respect to the iron distribution (Figure 5), iron deficiency treatment induced an increase in the leaf iron proportion. Notably, the leaf iron proportions in ZQ and $\mathrm{XC}$ were significantly higher than those in TO, regardless of iron treatments. The opposite trend was observed for relative root iron proportion.

\section{Transcriptome Changes in Response to Iron Deficiency}

To investigate transcriptomic changes happened after $24 \mathrm{~h}$ iron deficiency, RNA was extracted from ZQ, XC, and TO roots and used to construct cDNA libraries. More than 12 million total reads per library were obtained and greater than $99.59 \%$ of total reads were identified as clean reads (Supplementary Table S2). Based on a sequence saturation analysis, the number of detected genes was saturated and the sequencing depth was sufficient for gene expression analysis (data not shown). The total clean reads were then mapped to the sweet orange genome ${ }^{6}$. A total of 24,140 transcripts were detected (Supplementary Tables S2, S3). The expression level of each gene was normalized and evaluated by the FPKM approach (Supplementary Table S4); detailed expression and annotation information is provided in Supplementary Table S3. DEGs were defined (Supplementary Table S5). Functional analyses of DEGs were performed, including KEGG pathways (Supplementary Table S6) and a GO analysis (Supplementary Table S7).

In ZQ, only 29 genes were differentially expressed in response to iron deficiency, including 10 up-regulated and 19 downregulated genes. In XC, 298 genes were differentially expressed, including 232 up-regulated and 66 down-regulated genes. In TO, 400 genes were differentially expressed, including 234 upregulated and 166 down-regulated genes (Figure 6). Among these DEGs, only two (Cs4g18450 and Orange1.1t00580) were

\footnotetext{
${ }^{6}$ http://citrus.hzau.edu.cn/orange/index.php
} 

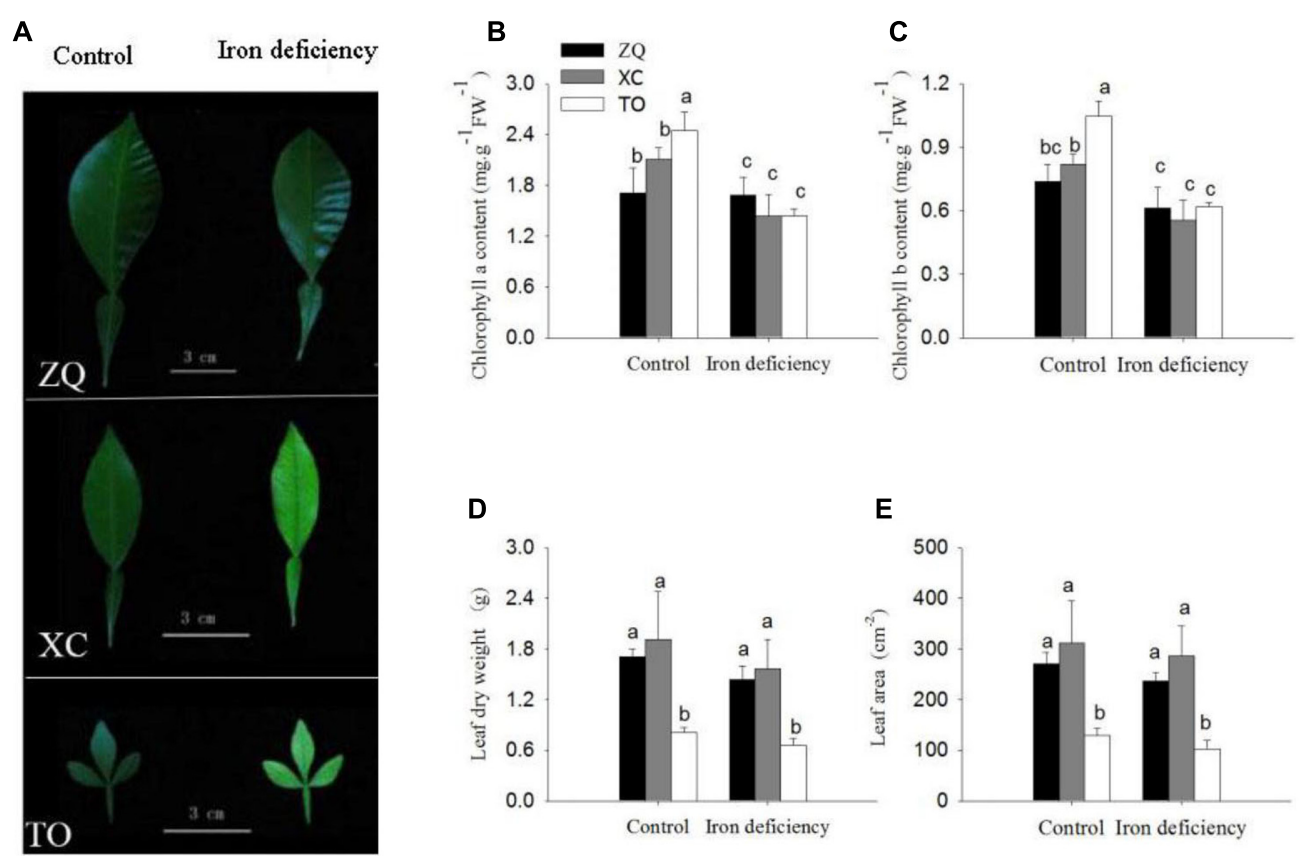

FIGURE 1 | Difference in leaf growth parameters of Zhique (ZQ), Xiangcheng $(X C)$, and trifoliate orange $(T O)$ grown in control and iron deficiency nutrient solution for 100 days. (A) Leaf morphology in ZQ, XC, and TO. (B,C) Chlorophyll concentration of leaves in ZQ, XC, and TO. (D,E) Leaf dry weight and leaf area of leaves in ZQ, $\mathrm{XC}$, and TO. Letters $(\mathrm{a}, \mathrm{b}$, and $\mathrm{c}$ ) indicate significant differences within samples via Duncan's multiple range test $P<0.05$ (Means $\pm \mathrm{SEM}, n=3$ ).

A

A Control Iron deficiency
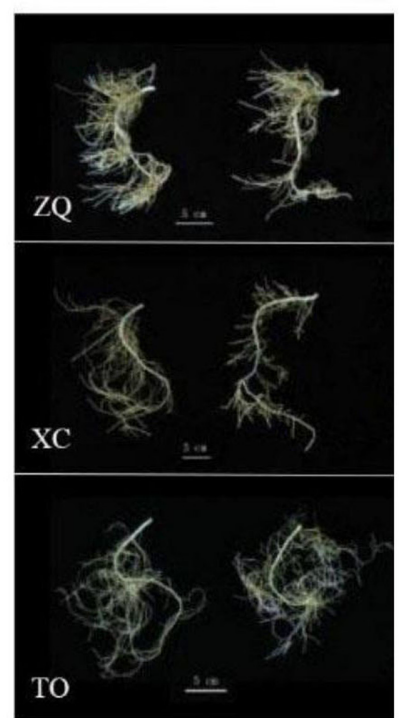

B

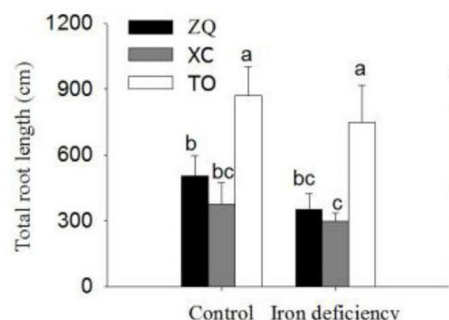

D

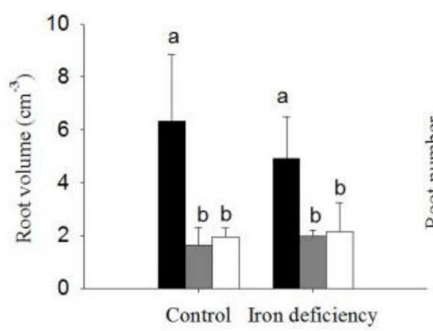

C

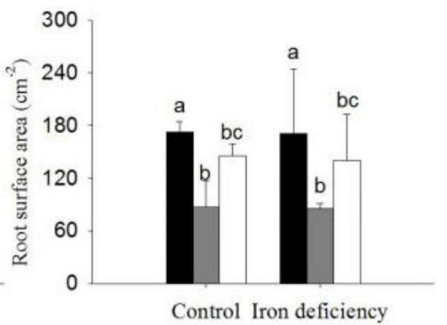

$E$

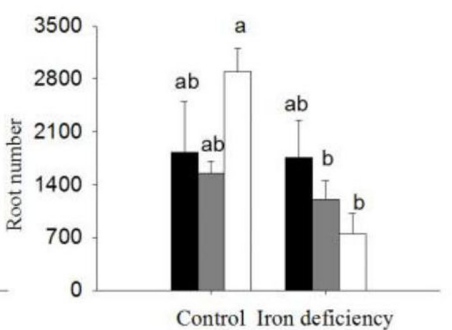

FIGURE 2 | Root growth parameters of ZQ, XC, and TO grown in control and iron deficiency nutrient solution for 100 days. (A) Root morphology in ZQ, XC, and TO. (B-E) Root growth parameters in ZQ, XC and TO. Letters ( $\mathrm{a}, \mathrm{b}$, and $\mathrm{c}$ ) indicate significant differences within samples via Duncan's multiple range test $P<0.05$ (Means \pm SEM, $n=3$ ).

common to the three rootstocks. Five DEGs were common to both ZQ and XC, 7 DEGs were common to both ZQ and TO, and 52 DEGs were common to both XC and TO. Functional categories of the DEGs are summarized in Figure 7. The major categories were "transport" (13.79\%), "protein" (6.90\%), and "stress" (6.90\%) in ZQ, "RNA" (12.65\%), "signaling" (8.24\%), 

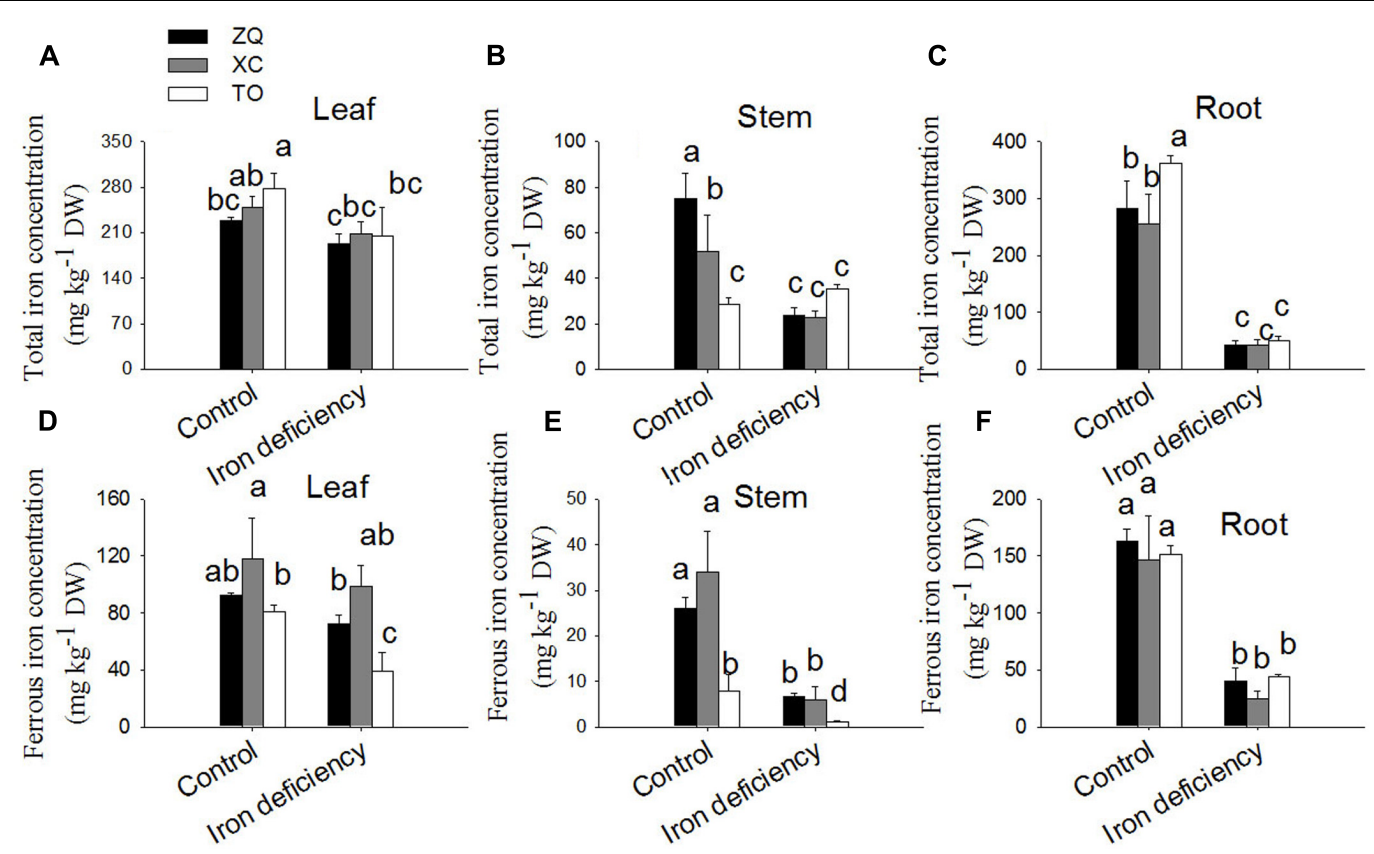

FIGURE 3 | Total Fe and ferrous Fe concentrations in ZQ, XC, and TO grown in control and iron deficiency nutrient solution for 100 days. (A-C) Total iron concentrations in ZQ, XC, and TO. (D-F) Ferrous iron concentrations in ZQ, XC, and TO. Data are shown as means \pm SEM ( $n=3$ ). Letters (a, b, and c) indicate significant differences within samples via Duncan's multiple range test $P<0.05$ (Means $\pm \mathrm{SEM}, n=3$ ).

and "protein" (7.65\%) in XC, and "protein" (11.19\%), "stress" (10.07\%), and "RNA" (9.17\%) in TO. In addition, genes involved in "hormone metabolism," "cell," and "secondary metabolism" were also highly represented in the three rootstocks. To validate the RNA-seq results, expression levels of 20 DEGs in ZQ, XC, and TO were determined by real-time PCR. As expected, 17 out of 20 genes in ZQ, 19 out of 20 in XC, and 16 out of 20 in TO showed the same expression as detected by RNA-seq (Supplementary Figure S5), suggesting that the transcriptomic data is reliable.

The conservation of the mechanisms underlying the response to iron deficiency among citrus and other plant species were examined. The DEGs identified in $\mathrm{ZQ}, \mathrm{XC}$, and TO were compared with iron deficiency-related transcriptome data obtained for other species, including Malus xiaojinensis, Poncirus trifoliate, Medicago truncatula, and Arabidopsis thaliana (O’Rourke et al., 2009; Yang et al., 2010; Rodríguez-Celma et al., 2013a,b; Wang et al., 2014). The DEGs of the plant species under iron deficiency were blasted against the Arabidopsis whole genome sequences ${ }^{7}$ to search for homologs with an $E$-value $=1 \times \mathrm{e}^{-5}$ or lower. This approach yielded 17 genes responsive to iron deficiency in $\mathrm{ZQ}, \mathrm{XC}$, TO, Malus xiaojinensis, Poncirus trifoliate, Medicago truncatula, and Arabidopsis thaliana (Table 1). The genes were associated with hormone synthesis and signaling, transcription, transportation, cell wall modification, and degradation, indicating that these genes or biological processes might be conserved in iron homeostasis in both woody and herbaceous plants.

${ }^{7}$ http://www.arabidopsis.org/servlets/TairObject?type=gene\&id=137982

\section{Iron Related Genes Specifically Expressed under Different Iron Deficiency Period}

Iron related genes were identified by a homology search with genes from sweet orange genome (Xu et al., 2012). Iron related genes such as FRO gene coding the plasma membrane ferric chelate reductase enzymes, and IRT gene coding for the iron transporter (Figure 8), were analyzed by quantitative real-time PCR at $0,24 \mathrm{~h}, 48,72$, and $96 \mathrm{~h}$ of iron deficiency treatments.

The expression of the FRO gene did not show any significant changes with regard to 24,48 , and $72 \mathrm{~h}$ iron deficiency in roots of $\mathrm{ZQ}$ and $\mathrm{XC}$ whereas FRO expression in both rootstocks increased significantly at $96 \mathrm{~h}$ iron deficiency. The FRO expression in TO was same to ZQ and XC at 24 and $48 \mathrm{~h}$ iron deficiency, whereas it was up-regulated at both 72 and $96 \mathrm{~h}$ iron deficiency in TO.

Iron-regulated transporter expression in $\mathrm{ZQ}$ and $\mathrm{XC}$ showed significantly up-regulated at 48, 72, and $96 \mathrm{~h}$ iron deficiency. However, the expression of IRT in TO was not significantly changed during the iron deficiency treatments.

\section{DISCUSSION}

\section{Physiological Mechanism of Tolerance to Iron Deficiency in Citrus Rootstocks}

Zhique and $\mathrm{XC}$ are more tolerant to iron deficiency than TO (Li et al., 2001; Fu et al., 2016), consistent with our results showing that the ZQ and XC had better physiological performance under iron deficiency. Generally, the leaves were highly affected by iron 

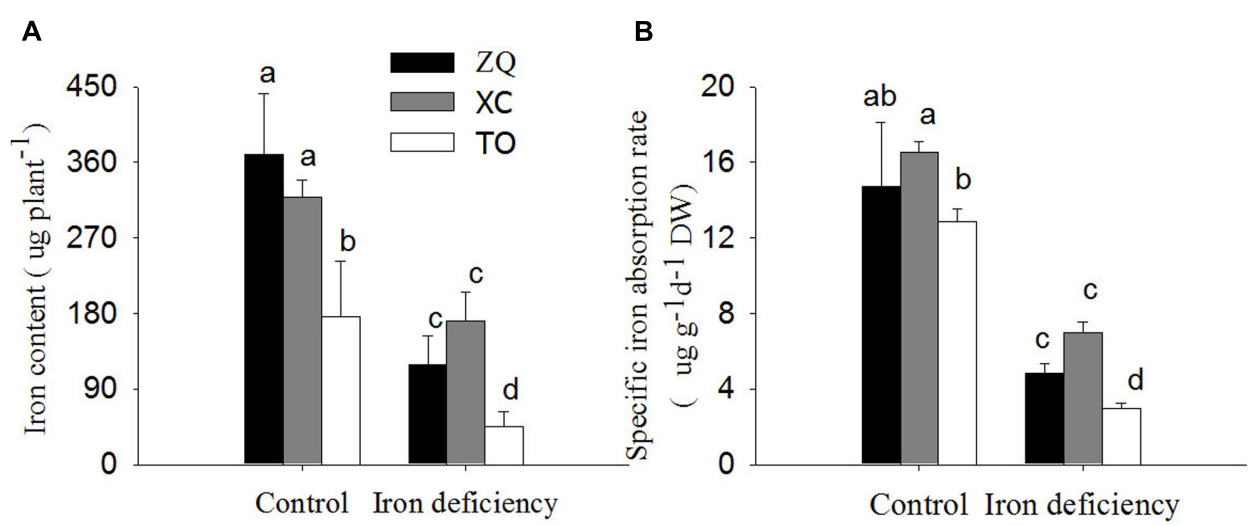

FIGURE 4 | Fe content per plant and specific Fe absorption rate in ZQ, XC, and TO grown in control and iron deficiency nutrient solution for 100 days. (A) Fe content per plant in ZQ, XC, and TO. (B) Specific Fe absorption rate in ZQ, XC, and TO. Letters (a, b, and c) indicate significant differences within samples via Duncan's multiple range test $P<0.05$ (Means $\pm \mathrm{SEM}, n=3$ ).

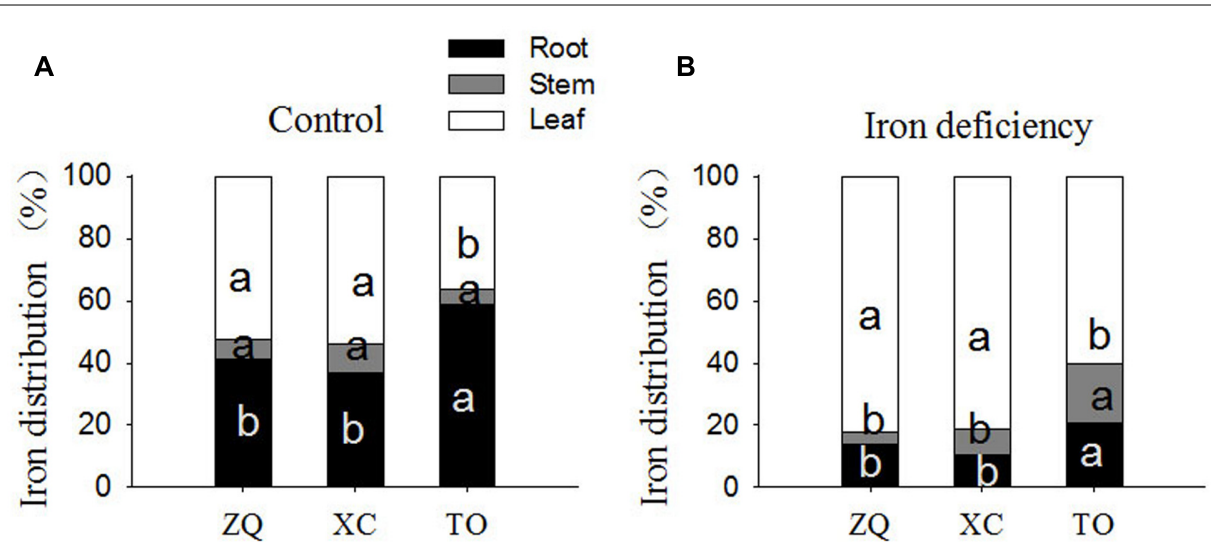

FIGURE 5 | Fe distribution in roots, stems and leaves of ZQ, XC, and TO grown in control and iron deficiency nutrient solution for 100 days. (A) Fe distribution in roots, stems, and leaves of ZQ, XC, and TO under control. (B) Fe distribution in roots, stems and leaves of ZQ, XC, and TO under iron deficiency. Letters (a, b, and c) indicate significant differences within samples via Duncan's multiple range test $P<0.05$ (Means $\pm \mathrm{SEM}, n=3$ ).
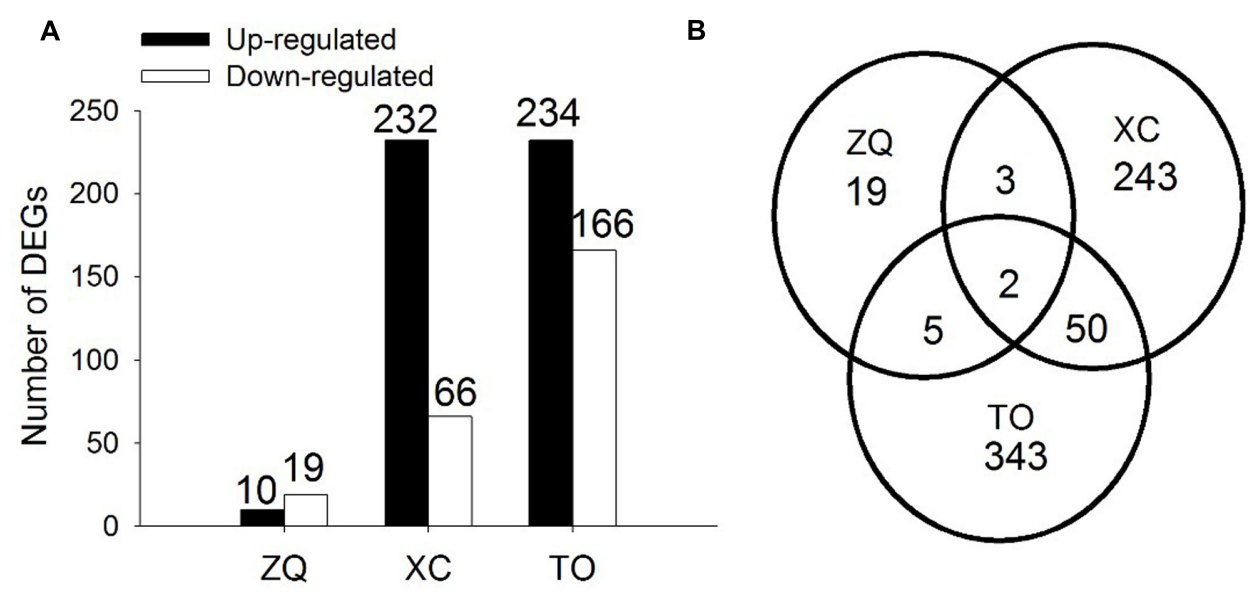

FIGURE 6 | Differentially Expressed Genes in roots of citrus rootstocks in $24 \mathrm{~h}$ of control and iron deficiency conditions. (A) Numbers of differentially expressed genes. (B) Venn diagram showing the number of genes that are differentially expressed in ZQ, XC, and TO, including shared and independent genes. 


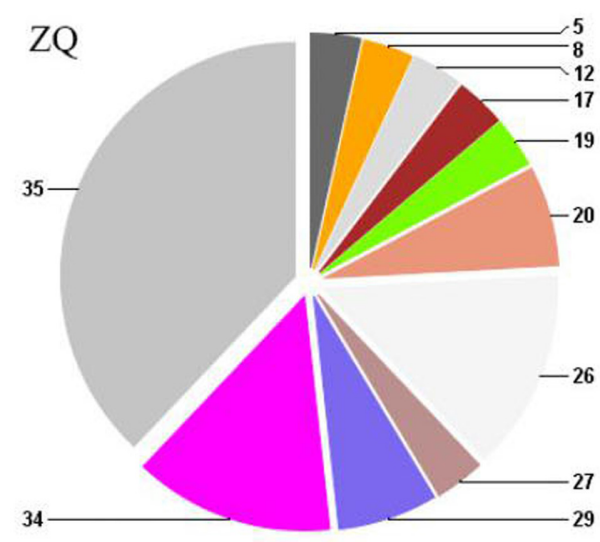

\begin{tabular}{|c|c|c|c|}
\hline 5- fermentation & $3.45 \%$ & $\begin{array}{l}=8 \cdot{ }^{T} \text { TCA /org } \\
\text { transformation }\end{array}$ & $3.45 \%$ \\
\hline 12 -N-metabolism & $3.45 \%$ & = 17 - hormone metabolism & $3.45 \%$ \\
\hline 19 - tetrapyrrole synthesis & $3.45 \%$ & in 20 -stress & $6.90 \%$ \\
\hline $26-m i s c$ & $13.79 \%$ & w $27 \cdot R N A$ & $3.45 \%$ \\
\hline III $29-$ protein & $6.90 \%$ & M3-transport & $13.79 \%$ \\
\hline$=35$ - not assigned & $37.93 \%$ & & \\
\hline
\end{tabular}

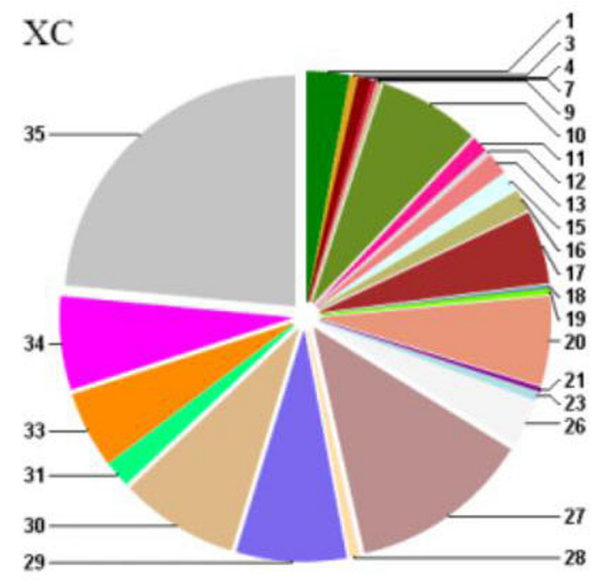

\begin{tabular}{|c|c|c|c|}
\hline =1. PS & $299 \%$ & $\begin{array}{l}\text { 3. minor CHO } \\
\text { motabolism }\end{array}$ & $0.59 \%$ \\
\hline 4. glycolysis & $0.88 \%$ & $=7 \cdot \mathrm{OPP}$ & $0.29 \%$ \\
\hline $\begin{array}{l}\text { =9. anitochondrial } \\
\text { electron transport/ } \\
\text { ATP symthesis }\end{array}$ & $0.29 \%$ & $=10-\mathrm{cell}$ wall & $7.06 \%$ \\
\hline = 11 . lipid metabolism & 1. $18 \%$ & $12 \cdot$ N-metabolism & $0.29 \%$ \\
\hline $\begin{array}{l}=13 \cdot \text { amino acid } \\
\text { aletabolisat }\end{array}$ & $1.47 \%$ & 15- metal Aandling & $1.57 \%$ \\
\hline $\begin{array}{l}16 \text { - secomdary } \\
\text { metabofisar }\end{array}$ & $1.47 \%$ & = 17 - hormome metabolism & $5.00 \%$ \\
\hline 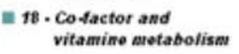 & $0.29 \%$ & $=19 \cdot$ tetrapyirole synthesis & $0.29 \%$ \\
\hline$=20 \cdot$ stress & $6.18 \%$ & $=21 \cdot$ - tedax & $2.29 \%$ \\
\hline $\begin{array}{l}23 \cdot \text { - macleotide } \\
\text { metabolisar }\end{array}$ & $0.59 \%$ & 26 - misc & $3.24 \pi$ \\
\hline$=27 \cdot R N A$ & $1265 \%$ & 28 - DNA & $0.59 \%$ \\
\hline$\equiv 29 \cdot$ protein & $7.65 \%$ & = 30 -signalling & $8.2 \%$ \\
\hline$=31 \cdot c e l l$ & $1.76 \%$ & $=33$ - development & $5.29 \%$ \\
\hline$=34 \cdot$ transport & 6.975 & il 35 - not assigned & $2353 \%$ \\
\hline
\end{tabular}

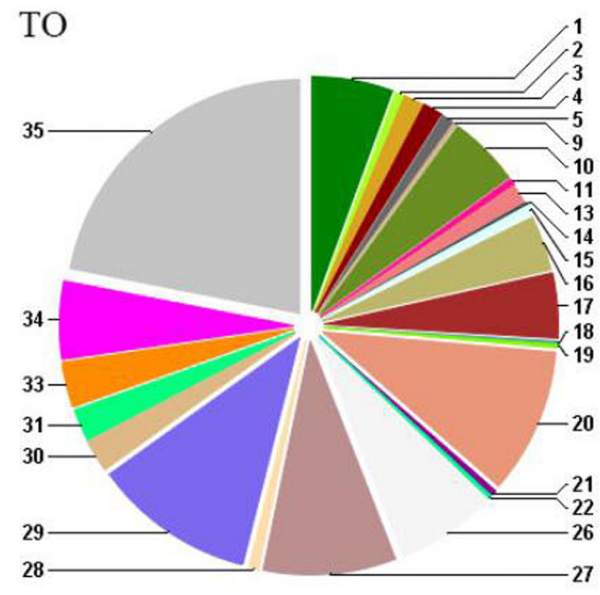

\begin{tabular}{|c|c|c|c|}
\hline =1.PS & $5.59 \%$ & $\begin{array}{l}\text { 2- major } \mathrm{CHO} \\
\text { metabolism }\end{array}$ & $0.67 \%$ \\
\hline = 3- minor $\mathrm{CHO}$ & $1.34 \%$ & " 4. giycolysis & $1.34 \%$ \\
\hline 5- fermentation & $0.89 \%$ & $\begin{array}{l}\text { 9- mitochondrial } \\
\text { electron transport/ } \\
\text { ATP synthesis }\end{array}$ & $0.22 \%$ \\
\hline 10 -cell wall & $4.92 \%$ & 11 - lipid metabolism & $0.45 \%$ \\
\hline $\begin{array}{l}13 \cdot \text { amino acid } \\
\text { metabolism }\end{array}$ & $1.34 \%$ & 14 -S assimilation & $0.22 \%$ \\
\hline 15 - metal handling & $0.67 \%$ & $\begin{array}{l}16 \text { - secondary } \\
\text { metabofism }\end{array}$ & $3.80 \%$ \\
\hline = 17 - hormone metabolism & $4.47 \%$ & $\begin{array}{l}\text { =18-Co-factor and } \\
\text { vitamine metabolism }\end{array}$ & $0.22 \%$ \\
\hline 19 - tetrapyrrole synthesis & $0.22 \%$ & $=20$-stress & $10.07 \%$ \\
\hline $21-$ redox & $0.45 \%$ & $\begin{array}{c}22 \text {-polyamine } \\
\text { metabolism }\end{array}$ & $0.22 \%$ \\
\hline $26-m i s c$ & $6.94 \%$ & $=27 \cdot R N A$ & $9.17 \%$ \\
\hline $28 \cdot$ - DNA & $0.67 \%$ & E29-protein & $11.19 \%$ \\
\hline W0 - signalling & $2.24 \%$ & $31-c e / 1$ & $224 \%$ \\
\hline m 33 -development & $3.13 \%$ & $=34-$ transport & $5.37 \%$ \\
\hline \# 35 - not assigned & $21.92 \%$ & & \\
\hline
\end{tabular}

FIGURE 7 | Main functional categories for differentially expressed genes according to MapMan functional plant categories.

deficiency in TO, as evidenced by observed chlorosis, whereas minor effects on the growth of stems and roots were detected. Accordingly, the reduction rate of chlorophyll $\mathrm{a}$ and $\mathrm{b}$ contents were higher in $\mathrm{TO}$ than in $\mathrm{ZQ}$ and $\mathrm{XC}$. Interestingly, they might be different tolerant mechanism to iron deficiency as ZQ and XC have very different levels of iron deficiency chlorosis. Considering the important role of iron in chlorophyll synthesis and chloroplast structure formation (Marschner and Römheld, 
TABLE 1 | A subset of differentially expressed genes conserved in citrus and several other species under iron deficiency.

\begin{tabular}{|c|c|c|c|c|c|c|c|c|}
\hline Citrus gene ID & Gene annotation & $Z Q\left(\log _{2}\right)$ & $x C\left(\log _{2}\right)$ & $\mathrm{TO}\left(\log _{2}\right)$ & $\begin{array}{c}\text { Malus } \\
\text { xiaojinensis }\end{array}$ & $\begin{array}{c}\text { Poncirus } \\
\text { trifoliata }\end{array}$ & $\begin{array}{l}\text { Medicago } \\
\text { truncatula }\end{array}$ & $\begin{array}{c}\text { Arabidopsis } \\
\text { thaliana }\end{array}$ \\
\hline Cs3g19420 & Ethylene-responsive transcription factor 012 & -1.46 & 2.91 & 2.54 & & $\sqrt{ }$ & & \\
\hline Cs9g13610 & Ethylene-responsive transcription factor 105 & -0.10 & 2.44 & 1.11 & $\sqrt{ }$ & & & \\
\hline Cs4g12540 & Ethylene synthesis/degradation & 0.57 & -6.25 & -5.57 & & & & $\sqrt{ }$ \\
\hline Cs3g26100 & Gibberellin-regulated protein 1 & 0.38 & 1.18 & 1.03 & & & $\sqrt{ }$ & $\sqrt{ }$ \\
\hline Cs5g03420 & BTB/POZ domain-containing protein & -0.01 & 2.82 & 1.00 & & & $\sqrt{ }$ & \\
\hline Cs2g03240 & Protein TIFY 5A & -0.92 & 2.47 & 1.50 & & & $\sqrt{ }$ & \\
\hline Cs4g10930 & Late embryogenesis abundant protein Lea14-A & -0.09 & 1.63 & -1.04 & & & $\sqrt{ }$ & \\
\hline Cs5g10740 & Geranylgeranyl diphosphate Reductase & -0.21 & 1.58 & 0.99 & & & & \\
\hline Cs7g21230 & Exostosin-like 3 & -0.05 & 1.30 & 1.19 & & & $\sqrt{ }$ & \\
\hline orange1.1t00580 & Myb-like protein $\mathrm{G}$ & -1.88 & -1.69 & -2.32 & & & $\sqrt{ }$ & \\
\hline Cs6g19940 & $\mathrm{Na}^{+}$dependent neutral amino acid transporter & -0.65 & -1.78 & -1.48 & & & $\sqrt{ }$ & \\
\hline Cs3g15140 & Nicotianamine synthase & -0.97 & -2.28 & -1.19 & & & & $\sqrt{ }$ \\
\hline Cs2g28870 & Peptide transporter PTR1 & -0.50 & -2.62 & -1.52 & & & & $\sqrt{ }$ \\
\hline Cs8g12690 & Phosphoenolpyruvate carboxylase kinase 1 & 0.05 & -2.74 & -1.19 & & & $\sqrt{ }$ & $\sqrt{ }$ \\
\hline Cs4g03210 & Xyloglucan endotransglucosylase protein & -1.77 & 3.24 & 2.31 & & & $\sqrt{ }$ & \\
\hline Cs2g02310 & Uncharacterized protein & -0.20 & -2.77 & -2.12 & & & & $\sqrt{ }$ \\
\hline Cs9g02930 & Flavone synthase & 1.24 & -6.28 & -5.83 & & & & $\sqrt{ }$ \\
\hline
\end{tabular}

Data in bold represent differentially expressed genes.

1995; Soldatini et al., 2000; M'sehli et al., 2009), our results indicated that iron contents or activities might be different among the leaves of the three rootstock seedlings.

As predicted, under iron deficiency treatment, the total iron and ferrous iron concentrations in leaves were significantly decreased in TO, but not in ZQ and XC. It is interesting that, under iron deficiency, though the total iron concentrations did not differ among $\mathrm{ZQ}, \mathrm{XC}$, and $\mathrm{TO}$, the ferrous iron concentration iron in $\mathrm{ZQ}$ and $\mathrm{XC}$ were much higher than that in TO. These results supported a previous hypothesis that the ferrous

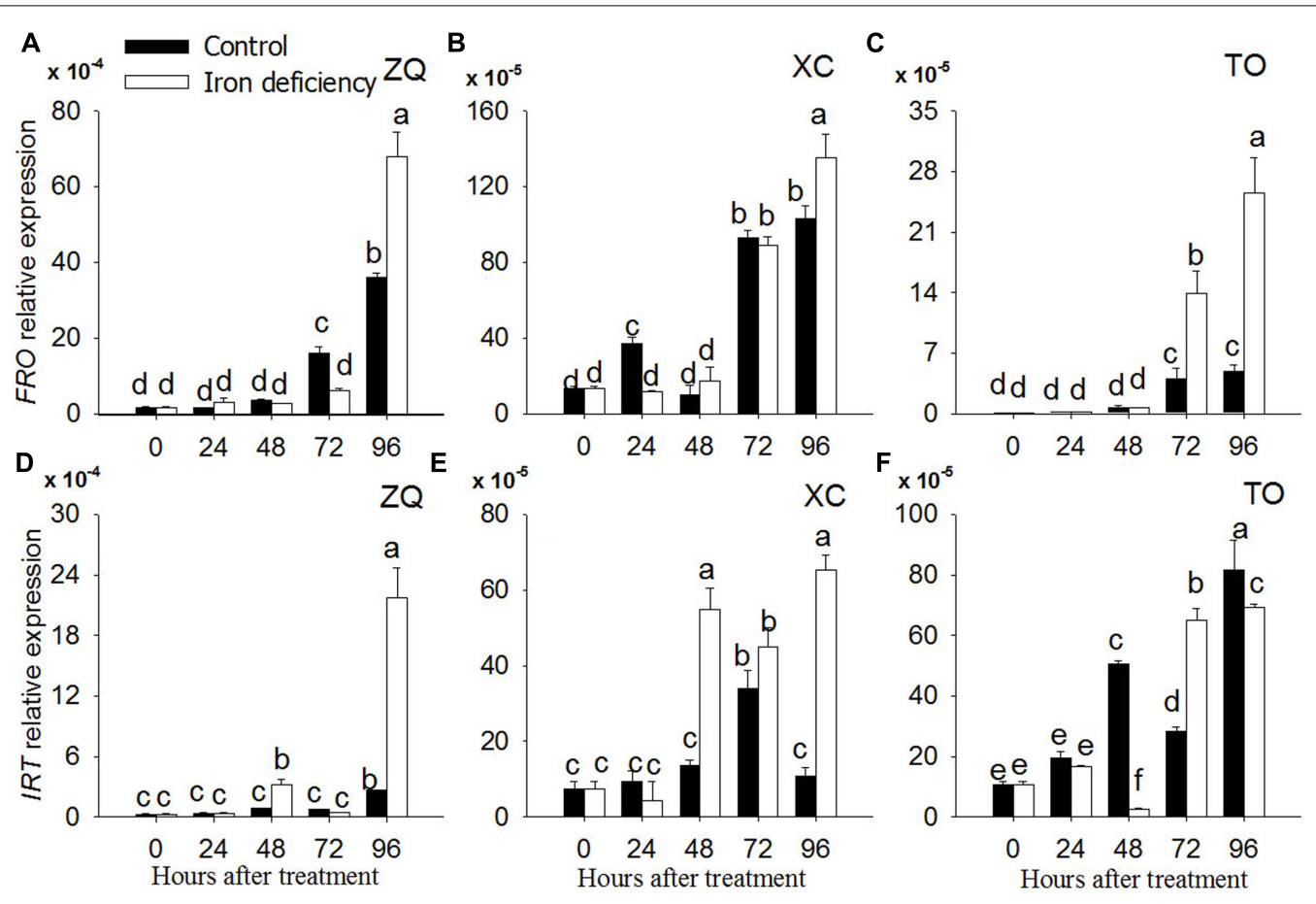

FIGURE 8 | Gene expression of FRO and IRT in ZQ, XC and TO under iron deficiency for $0,24,48,72$, and 96 h. (A,D) The expression of FRO and IRT genes in ZQ. (B,E) The expression of FRO and IRT genes in XC. (C,F) The expression of FRO and IRT genes in TO. 
concentration is an important indicator of iron deficiencytolerance (Dasgan et al., 2003; Ksouri et al., 2006; Jelali et al., 2011; Fu et al., 2016), which could be further used to diagnose iron-deficiency symptom in citrus cultivation management. It is worth mentioning that both the total and ferrous iron in roots showed no differences among the three rootstocks, different from our previous results showing that the ferrous iron concentration in roots of $\mathrm{ZQ}$ was significantly higher than that in the roots of TO. This difference might be explained by (i) a difference in sample origin (the previous samples were collected in field conditions while samples from this study are from hydroponic culture), and (ii) a possible scion-rootstock combination effect in the previous study (mandarin/rootstock grafted trees), while rootstock seedlings were analyzed in this study.

A decrease in the ferrous iron concentration in leaves might be a consequence of lower iron uptake by roots and/or impaired iron translocation from roots to shoots. To clarify this, the iron content per plant, specific iron absorption rate, and iron distribution in different tissues of three rootstocks were investigated. Both the iron content per plant and specific iron absorption rate in iron deficiency-tolerant $\mathrm{ZQ}$ and $\mathrm{XC}$ were higher than those in iron deficiency sensitive TO under iron deficiency. Consistent with our results, Martínez-Cuenca et al. (2013) observed a greater increase in the iron uptake rate in the tolerant rootstock Cleopatra mandarin than in the iron deficiency-sensitive Carrizo citrange. These results indicate that, under iron deficiency, the tolerant rootstocks are more efficient in iron uptake by roots. In addition, our results showed that iron deficiency promotes the increase in the leaf iron distribution in all three rootstocks, but the leaf iron proportion in $\mathrm{ZQ}$ and $\mathrm{XC}$ were higher than those in TO. Together, our results indicated that tolerance to iron deficiency might be explained by increased iron uptake in the roots of $\mathrm{ZQ}$ and XC, and subsequently, increased translocation of iron from roots to shoots.

\section{Genes Associated with Iron Deficiency Acclimation in Citrus Rootstock}

A comparative transcriptome analysis was performed to investigate the molecular mechanism underlying iron uptake in the roots of $\mathrm{ZQ}, \mathrm{XC}$, and TO under iron deficiency. More DEGs were detected in iron deficiency-sensitive TO than in ZQ and XC (400 genes against 298 and 29 genes, respectively). These results imply that the degree of molecular response could be arranged as $\mathrm{TO}>\mathrm{XC}>\mathrm{ZQ}$, contrary to the performance of three rootstocks in filed conditions, in which ZQ is the most tolerant to iron deficiency while TO is the most sensitive.

Well-known iron-related genes, such as FRO and IRT genes, were not detected in our transcriptome analysis. One DEG was annotated as iron transport protein 3 (Cs4g18450), but it was down-regulated by iron deficiency treatment in all three rootstocks. Iron transporters, such as IRT1 are up-regulated in other species, in transcriptome experiments regardless of growth conditions and duration of iron deficiency (Eide et al., 1996). The down-regulation of iron transport protein 3 in this study suggests that: (i) it may not be involved in iron uptake or (ii) it is an iron efflux gene, and its down-regulation under iron deficiency could prevent iron excretion and thus maintain more iron in root cells.

We infer that the absent of well-known iron-related genes such as FRO and IRT in DEG list may due to that the time $(24 \mathrm{~h})$ for iron deficiency treatment is not long enough, which was further confirmed by our quantitative PCR results. It was suggested that, different from herbaceous plants, the iron may be stored in apoplast which could be available for normal growth in woody plants (Martínez-Cuenca et al., 2013). However, after $24 \mathrm{~h}$ treatment, the expression levels of IRT gene in ZQ and XC were significantly up-regulated as compared with control, while it was relative stable in TO. As for FRO, its expression levels were similar in the three citrus rootstocks. The results may indicate that the expression of IRT rather than FRO is related with the higher iron uptake rate in ZQ and XC.

In total, 16 DEGs in $\mathrm{XC}$ and $\mathrm{TO}$ be involved in cell wall metabolism. Among them, 5 xyloglucan endotransglycosylase/hydrolase (XTH) genes in XC and TO were up-regulated under iron deficiency. XTH plays roles in cell wall modification by regulating cell wall strength and extensibility, and is involved in diverse environmental stress responses (Herbers et al., 2001; Wu et al., 2005; Cho et al., 2006). Notably, the expression level of all five XTH genes in XC were at least four times higher than those in TO, suggesting that the cell wall modification in iron deficiency was more intense in $\mathrm{XC}$ than in TO. In addition, one pectin lyase gene in $\mathrm{XC}$ and $\mathrm{TO}$ was down-regulated, suggesting that the roots provide more pectin for cell wall restructuring by inhibiting pectin degradation. Compared with TO, the expression level of the pectin lyase gene was much lower in XC. Forner-Giner et al. (2010) found that the cell wall becomes thinner in iron deficiency in TO, and this may result from cell wall restructuring in response to iron deficiency. Therefore, the results of our study implied that the up regulation of xyloglucan endotransglycosylase/hydrolase and the down regulation of pectin lyase may play important roles in response to iron deficiency by enhancing cell wall modifications, especially in tolerant rootstocks.

One gene in ZQ (down-regulated), 16 genes in XC (15 up-regulated and 1 down-regulated), and 10 genes in TO (6 up-regulated and 4 down-regulated) involved in ethylene metabolism were detected in our study. A total of 13 genes involved in ethylene metabolism increased more than twofold in XC under iron deficiency, and only one gene in TO show an increase of twofold. In total, 13 up-regulated genes in $\mathrm{XC}$ encoded ethylene-responsive transcription factors (ERF) involved in the ethylene signal transduction pathway. Consistent with our results, several ERF genes are also activated in response to early iron deficiency in iron deficiency-tolerant Malus xiaojinensis, suggesting that the ethylene signal pathway plays an important role in iron-tolerant species under iron deficiency conditions. Another ethylene transcription factor family including ETHYLENE INSENSITIVE3 (EIN3) and ETHYLENE INSENSITIVE3-LIKE1 (EIL1), physically interact with FIT and activate iron acquisition-related genes under iron deficiency conditions (Lingam et al., 2011). Moreover, ERF functions downstream of EIN3, which may regulate one branch of the ethylene response pathway (Wang et al., 2002). 
These studies imply that the ERF genes detected here may be involved in the up-stream regulation of the response to iron deficiency in iron deficiency-tolerant citrus rootstocks.

It is notable that eight genes involved in the abscisic acid (ABA) pathway, an early response to iron deficiency, were detected in TO, including 2 up-regulated and 6 down-regulated genes, but genes in this pathway were not detected in $\mathrm{ZQ}$ and $\mathrm{XC}$. Cs6g19380 (ABA 8'-hydroxylase) involved in ABA catabolism (Okamoto et al., 2006), was up-regulated and the Cs5g14370 (9-cis epoxycarotenoid dioxygenase, NCED), a key enzyme in the biosynthesis of ABA (Tan et al., 2003), was down-regulated. These data suggested that ABA biosynthesis was inhibited and the degradation process was activated in roots of TO under iron deficiency. In addition, an ABA-insensitive-like protein (cs3g23480) involved in ABA signal transduction (Gao et al., 2016) was also down-regulated in the roots of TO. Together, the iron deficiency-induced ABA metabolism response was only detected in the iron deficiency-sensitive rootstock TO and not in $\mathrm{ZQ}$ or $\mathrm{XC}$, strengthening the idea that $\mathrm{ZQ}$ and $\mathrm{XC}$ are indeed more tolerant than $\mathrm{TO}$, particularly considering that $\mathrm{ABA}$ is a stress response hormone.

\section{CONCLUSION}

Our study revealed two new findings: (i) iron deficiency-tolerance in citrus rootstocks could be due to a higher uptake rate of iron and increased iron translocation from roots to shoots, and (ii) the cell wall modification, ethylene, and ABA signaling pathways seemed are involved in the acclimation to iron deficiency in citrus rootstocks. This study investigated the physiological and molecular changes underlying tolerance to iron deficiency, and it will contribute to further understand the tolerance response in citrus plants.

\section{AUTHOR CONTRIBUTIONS}

LF, ZP, and SP conceived the design of this research. LF and QZ performed the bioinformatics data analysis. LF wrote the paper. $\mathrm{ZP}$ contributed to the statistical analyses and in the revising of the manuscript. QZ, YS, and WD contributed to the revising of the manuscript.

\section{REFERENCES}

An, J. C., Liu, Y. Z., Yang, C. Q., Zhou, G. F., Wei, Q. J., and Peng, S. A. (2012). Isolation and expression analysis of CiNIP5, a citrus boron transport gene involved in tolerance to boron deficiency. Sci. Hortic. 142, 149-154. doi: 10.1016/j.scienta.2012.05.013

Bacaicoa, E., and García-Mina, J. M. (2009). Fe efficiency in different cucumber cultivars: the importance of optimizing the use of foliar Fe. J. Am. Soc. Hortic. Sci. 134, 405-416.

Bellaloui, N., and Brown, P. H. (1998). Cultivar differences in boron uptake and distribution in celery (Apium graveolens), tomato (Lycopersicon esculentum) and wheat (Triticum aestivum). Plant Soil 198, 153-158. doi: 10.1023/A: 1004343031242

Carpena-Artes, O., Moreno, J. J., Lucena, J. J., and Carpena-Ruiz, R. O. (1995). Response to Iron Chlorosis of Different Hydroponically Grown

\section{FUNDING}

This study was supported by the National Natural Science Foundation of China (No. 31471841; 31521092), the Fundamental Research Funds for the Central Universities (No. 2662015PY061), and the earmarked fund for China Agriculture Research System (CARS-27).

\section{ACKNOWLEDGMENTS}

Authors would like to thank professor Yongzhong Liu and Syed B. Hussain for their contribution in the experimental procedures and in manuscript revise.

\section{SUPPLEMENTARY MATERIAL}

The Supplementary Material for this article can be found online at: http://journal.frontiersin.org/article/10.3389/fpls.2017.01104/ full\#supplementary-material

FIGURE S1 | Stem growth parameters of Zhique (ZQ), Xiangcheng (XC), and trifoliate orange (TO) grown in control and iron deficiency nutrient solution for 100 days. (A) Stem morphology in $Z Q, X C$, and TO. (B) Stem length in $Z Q, X C$, and TO. (C) Stem dry weight in ZQ, XC, and TO. Letters (a, b, and c) indicate significant differences within samples via Duncan's multiple range test $P<0.05$ (Means \pm SEM, $n=3$ ).

FIGURE S2 | Curve of sequencing saturation in ZQ. X-axis shows the number of clean reads, units is $100 \mathrm{k}$ - extreme value is currently the volume of sequencing. $Y$-axis shows the ratio of identified gene number to number of total gene reported in database.

FIGURE S3 | Curve of sequencing saturation in ZQ. X-axis shows the number of clean reads, units is $100 \mathrm{k}$ - extreme value is currently the volume of sequencing. $Y$-axis shows the ratio of identified gene number to number of total gene reported in database.

FIGURE S4 | Curve of sequencing saturation in ZQ. X-axis shows the number of clean reads, units is $100 \mathrm{k}$ - extreme value is currently the volume of sequencing. $Y$-axis shows the ratio of identified gene number to number of total gene reported in database.

FIGURE S5 | $\log _{2}$ transcription levels under iron deficiency relative to control levels estimated by qRT-PCR and by RNA-seq for ZQ, XC, and TO after $24 \mathrm{~h}$ of iron deficiency.

Citrus Varieties. Dordrecht: Springer, 147-151. doi: 10.1007/978-94-011-050 3-3_21

Castle, W. S., Nunnallee, J., and Manthey, J. A. (2009). Screening citrus rootstocks and related selections in soil and solution culture for tolerance to low-iron stress. Hortscience 44, 638-645.

Cho, S. K., Kim, J. E., Park, J. A., Eom, T. J., and Kim, W. T. (2006). Constitutive expression of abiotic stress-inducible hot pepper CaXTH3, which encodes a xyloglucan endotransglucosylase/hydrolase homolog, improves drought and salt tolerance in transgenic Arabidopsis plants. FEBS Lett. 580, 3136-3144. doi: 10.1016/j.febslet.2006.04.062

Curie, C., Panaviene, Z., Loulergue, C., Dellaporta, S. L., Briat, J. F., and Walker, E. L. (2001). Maize yellow stripe 1 encodes a membrane protein directly involved in Fe (III) uptake. Nature 409, 346-349. doi: 10.1038/35053080

Dasgan, H. Y., Ozturk, L., Abak, K., and Cakmak, I. (2003). Activities of ironcontaining enzymes in leaves of two tomato genotypes differing in their 
resistance to Fe chlorosis. J. Plant Nutr. 26, 1997-2007. doi: 10.1081/PLN120024259

Dell'Orto, M., Santi, S., De Nisi, P., Cesco, S., Varanini, Z., Zocchi, G., et al. (2000). Development of Fe-deficiency responses in cucumber (Cucumis sativus L.) roots: involvement of plasma membrane $\mathrm{H}^{+}$-ATPase activity. J. Exp. Bot. 51, 695-701. doi: 10.1093/jexbot/51.345.695

Eide, D., Broderius, M., Fett, J., and Guerinot, M. L. (1996). A novel iron-regulated metal transporter from plants identified by functional expression in yeast. Proc. Natl. Acad. Sci. U.S.A. 93, 5624-5628. doi: 10.1073/pnas.93.11.5624

Fernández, V., Winkelmann, G., and Ebert, G. (2004). Iron supply to tobacco plants through foliar application of iron citrate and ferric dimerum acid. Physiol. Plant. 122, 380-385. doi: 10.1111/j.1399-3054.2004.00405.x

Forner-Giner, M. A., Llosá, M. J., Carrasco, J. L., Perez-Amador, M. A., Navarro, L., and Ancillo, G. (2010). Differential gene expression analysis provides new insights into the molecular basis of Fe deficiency stress response in the citrus rootstock Poncirus trifoliata (L.) Raf. J. Exp. Bot. 61, 483-490. doi: 10.1093/jxb/ erp328

Fu, L. N., Chai, L. J., Ding, D. K., Pan, Z. Y., and Peng, S. A. (2016). A novel citrus rootstock tolerant to iron deficiency in calcareous soil. J. Am. Soc. Hort. Sci. 141, $112-118$.

Gao, S., Gao, J., Zhu, X. Y., Song, Y., Li, Z. P., Ren, G. D., et al. (2016). ABF2, ABF3, and $\mathrm{ABF} 4$ promote $\mathrm{ABA}$-mediated chlorophyll degradation and leaf senescence by transcriptional activation of chlorophyll catabolic genes and senescenceassociated genes in Arabidopsis. Mol. Plant 9, 1272-1285. doi: 10.1016/j.molp. 2016.06.006

Herbers, K., Lorences, E. P., Barrachina, C., and Sonnewald, U. (2001). Functional characterisation of Nicotiana tabacum xyloglucan endotransglycosylase (NtXET-1): generation of transgenic tobacco plants and changes in cell wall xyloglucan. Planta 212, 279-287. doi: 10.1007/s004250000393

Hoagland, D. R., and Arnon, D. S. (1950). The water-culture method for growing plants without soil. Circ. Cal. Agric. Exp. St. 347, 305-311.

Jelali, N., Imen, B. S., Wissal, M., Silvia, D., Graziano, Z., and Mohamed, G. (2011). Comparison of three pea cultivars (Pisum sativum) regarding their responses to direct and bicarbonate-induced iron deficiency. Sci. Hortic. 129, 548-553. doi: 10.1016/j.scienta.2011.06.010

Ksouri, R., Debez, A., Mahmoudi, H., Ouerghi, Z., Gharsalli, M., and Lachaâl, M. (2007). Genotypic variability within Tunisian grapevine varieties (Vitis vinifera L.) facing bicarbonate-induced iron deficiency. Plant Physiol. Biochem. 45, 315-322. doi: 10.1016/j.plaphy.2007.03.014

Ksouri, R., M'rah, S., Gharsalli, M., and Lachaâl, M. (2006). Biochemical responses to true and bicarbonate-induced iron deficiency in grapevine genotypes. J. Plant Nutr. 29, 305-315. doi: 10.1080/01904160500476897

Li, B., and Dewey, C. N. (2011). RSEM: accurate transcript quantification from RNA-Seq data with or without a reference genome. BMC Bioinformatics 12:323. doi: 10.1186/1471-2105-12-323

Li, L., Fan, Y. H., Luo, X. Y., Zhou, Z. Y., and Pei, Y. (2001). Study on ferric chelate reductase of Citrus junos and Poncirus trifoliata. J. Southwest Agric. Univ. 5:015.

Li, R., Yu, C., Li, Y., Lam, T. W., Yiu, S. M., Kristiansen, K., et al. (2009). SOAP2: an improved ultrafast tool for short read alignment. Bioinformatics 25, 1966-1967. doi: 10.1093/bioinformatics/btp336

Licciardello, C., Torrisi, B., Allegra, M., Sciacca, F., Roccuzzo, G., Intrigliolo, F., et al. (2013). A transcriptomic analysis of sensitive and tolerant citrus rootstocks under natural Fe deficiency conditions. J. Am. Soc. Hortic. Sci. 138, 487-498.

Lingam, S., Mohrbacher, J., Brumbarova, T., Potuschak, T., Fink-Straube, C., Blondet, E., et al. (2011). Interaction between the bHLH transcription factor FIT and ETHYLENE INSENSITIVE3/ETHYLENE INSENSITIVE3-LIKE1 reveals molecular linkage between the regulation of iron acquisition and ethylene signaling in Arabidopsis. Plant Cell 23, 1815-1829. doi: 10.1105/tpc.111.084715

Livak, K. J., and Schmittgen, T. D. (2001). Analysis of relative gene expression data using real-time quantitative PCR and the $2^{-\Delta \Delta C_{T}}$ method. Methods 25, 402-408. doi: 10.1006/meth.2001.1262

Lohse, M., Nagel, A., Herter, T., May, P., Schroda, M., Zrenner, R., et al. (2014). Mercator: a fast and simple web server for genome scale functional annotation of plant sequence data. Plant Cell Environ. 37, 1250-1258. doi: 10.1111/pce. 12231

Marschner, H., and Römheld, V. (1995). "Strategies of plants for acquisition of iron," in Iron Nutrition in Soils and Plants, ed. J. Abadía (Dordrecht: Kluwer Academic Press), 375-388.
Martínez-Cuenca, M. R., Forner-Giner, M. Á, Iglesias, D. J., Primo-Millo, E., and Legaz, F. (2013). Strategy I responses to Fe-deficiency of two Citrus rootstocks differing in their tolerance to iron chlorosis. Sci. Hortic. 153, 56-63. doi: 10. 1016/j.scienta.2013.01.009

Mimmo, T., Del Buono, D., Terzano, R., Tomasi, N., Vigani, G., Crecchio, C., et al. (2014). Rhizospheric organic compounds in the soil-microorganismplant system: their role in iron availability. Eur. J. Soil Sci. 65, 629-642. doi: 10.1111/ejss. 12158

Molassiotis, A., Tanou, G., Diamantidis, G., Patakas, A., and Therios, I. (2006). Effects of 4-month Fe deficiency exposure on Fe reduction mechanism, photosynthetic gas exchange, chlorophyll fluorescence and antioxidant defense in two peach rootstocks differing in Fe deficiency tolerance. J. Plant Physiol. 163, 176-185. doi: 10.1016/j.jplph.2004.11.016

M'sehli, W., Dell'Orto, M., De Nisi, P., Donnini, S., Abdelly, C., Zocchi, G., et al. (2009). Responses of two ecotypes of Medicago ciliaris to direct and bicarbonate-induced iron deficiency conditions. Acta Physiol. Plant 31, 667-673. doi: 10.1007/s11738-009-0288-1

Okamoto, M., Kuwahara, A., Seo, M., Kushiro, T., Asami, T., Hirai, N., et al. (2006). CYP707A1 and CYP707A2, which encode ABA 8hydroxylases, are indispensable for proper control of seed dormancy and germination in Arabidopsis. Plant Physiol. 141, 97-107. doi: 10.1104/pp.106. 079475

O’Rourke, J. A., Nelson, R. T., Grant, D., Schmutz, J., Grimwood, J., Cannon, S., et al. (2009). Integrating microarray analysis and the soybean genome to understand the soybeans iron deficiency response. BMC Genomics 10:376. doi: 10.1186/1471-2164-10-376

Pestana, M., Varennes, A., de Abadia, J., and Faria, E. A. (2005). Differential tolerance to Fe deficiency of citrus rootstocks grown in nutrient solution. Sci. Hortic. 104, 25-36. doi: 10.1016/j.scienta.2004.07.007

Pii, Y., Marastoni, L., Springeth, C., Fontanella, M. C., Beone, G. M., Cesco, S., et al. (2016). Modulation of Fe acquisition process by Azospirillum brasilense in cucumber plants. Environ. Exp. Bot. 130, 216-225. doi: 10.1016/j.envexpbot. 2016.06.011

Pii, Y., Penn, A., Terzano, R., Crecchio, C., Mimmo, T., and Cesco, S. (2015). Plantmicroorganism-soil interactions influence the Fe availability in the rhizosphere of cucumber plants. Plant Physiol. Biochem. 87, 45-52. doi: 10.1016/j.plaphy. 2014.12.014

Robinson, N. J., Procter, C. M., Connolly, E. L., and Guerinot, M. L. (1999). A ferric-chelate reductase for iron uptake from soils. Nature 397, 694-697. doi: $10.1038 / 17800$

Rodríguez-Celma, J., Lin, W. D., Fu, G. M., Abadía, J., López-Millán, A. F., and Schmidt, W. (2013a). Mutually exclusive alterations in secondary metabolism are critical for the uptake of insoluble iron compounds by Arabidopsis and Medicago truncatula. Plant Physiol. 162, 1473-1485. doi: 10.1104/pp.113. 220426

Rodríguez-Celma, J., Pan, I., Li, W. D., Lan, P. D., Buckhout, T. J., and Schmidt, W. (2013b). The transcriptional response of Arabidopsis leaves to Fe deficiency. Front. Plant Sci. 4:276. doi: 10.3389/fpls.2013.00276

Rombolà, A. D., and Tagliavini, M. (2006). "Iron nutrition of fruit tree crops," in Iron Nutrition in Plants and Rhizospheric Microorganisms, ed. L. Barton (Dordrecht: Springer), 61-83. doi: 10.1007/1-4020-4743-6_3

Römheld, V., and Marschner, H. (1986). Evidence for a specific uptake system for iron phytosiderophores in roots of grasses. Plant Physiol. 80, 175-180. doi: $10.1104 /$ pp.80.1.175

Santi, S., and Schmidt, W. (2009). Dissecting iron deficiency-induced proton extrusion in Arabidopsis roots. New Phytol. 183, 1072-1084. doi: 10.1111/j. 1469-8137.2009.02908.x

Shenker, M., and Chen, Y. (2005). Increasing iron availability to crops: fertilizers, organo-fertilizers, and biological approaches. Soil Sci. Plant Nutr. 51, 1-17. doi: 10.1111/j.1747-0765.2005.tb00001.x

Soldatini, G. F., Tognini, M., Castagna, A., Baldan, B., and Ranieri, A. (2000). Alterations in thylakoid membrane composition induced by iron starvation in sunflower plants. J. Plant Nutr. 23, 1717-1732. doi: 10.1080/ 01904160009382136

Tan, B. C., Joseph, L. M., Deng, W. T., Liu, L., Li, Q. B., Cline, K., et al. (2003). Molecular characterization of the Arabidopsis 9-cis epoxycarotenoid dioxygenase gene family. Plant J. 35, 44-56. doi: 10.1046/j.1365-313X.2003. 01786.x 
Terrazas, R. A., Giles, C., Paterson, E., Robertson-Albertyn, S., Cesco, S., Mimmo, T., et al. (2016). Chapter one-plant-microbiota interactions as a driver of the mineral turnover in the rhizosphere. Adv. Appl. Microbiol. 95, 1-67. doi: 10.1016/bs.aambs.2016.03.001

Wang, K. L. C., Li, H., and Ecker, J. R. (2002). Ethylene biosynthesis and signaling networks. Plant Cell 14(Suppl. 1), S131-S151. doi: 10.1105/tpc.001768

Wang, S., Lu, B., Wu, T., Zhang, X., Xu, X., Han, Z., et al. (2014). Transcriptomic analysis demonstrates the early responses of local ethylene and redox signaling to low iron stress in Malus xiaojinensis. Tree Genet. Genomes 10, 573-584. doi: 10.1007/s11295-014-0705-5

Wu, Y., Jeong, B. R., Fry, S. C., and Boyer, J. S. (2005). Change in XET activities, cell wall extensibility and hypocotyl elongation of soybean seedlings at low water potential. Planta 220, 593-601. doi: 10.1007/s00425-004-1369-4

Xu, Q., Chen, L. L., Ruan, X., Chen, D., Zhu, A., Chen, C., et al. (2012). The draft genome of sweet orange (Citrus sinensis). Nat. Genet. 45, 59-66. doi: $10.1038 /$ ng. 2472
Yang, T. J., Lin, W. D., and Schmidt, W. (2010). Transcriptional profiling of the Arabidopsis iron deficiency response reveals conserved transition metal homeostasis networks. Plant Physiol. 152, 2130-2141. doi: 10.1104/pp.109. 152728

Conflict of Interest Statement: The authors declare that the research was conducted in the absence of any commercial or financial relationships that could be construed as a potential conflict of interest.

Copyright (c) $2017 \mathrm{Fu}, \mathrm{Zhu}, \mathrm{Sun}, \mathrm{Du}, \mathrm{Pan}$ and Peng. This is an open-access article distributed under the terms of the Creative Commons Attribution License (CC BY). The use, distribution or reproduction in other forums is permitted, provided the original author(s) or licensor are credited and that the original publication in this journal is cited, in accordance with accepted academic practice. No use, distribution or reproduction is permitted which does not comply with these terms. 